Effect of Haze on Solar Rotation Measures.The extensive determinations of the sun's rotation which have been made by the spectroscopic method have shown remarkable variations, even among results obtained at the same observatory at different times. Thus the values for the equatorial velocity range from I.86 to $2.1 \mathrm{I} \mathrm{km}$. per sec., and observers have not agreed as to the inequality of the values obtained from different lines at the same time. Again, while some observers have found values of the rate of rotation progressively increasing with the wave-length, many other observations have not shown this effect. A valuable contribution towards tracing the source of such discordances has been made by R. E. De Lury, of the Dominion Observatory, Ottawa, in a careful investigation of the effects of haze on the spectroscopic measurements (Journ. R.A.S. Canada, vol. x., p. 345). The effect of terrestrial atmospheric haze is obviously to superpose a weakened solar spectrum, coming mainly from the centre of the sun's disc and showing no displacements at all, upon the limb spectra. The measured displacements of the blended lines at the limb would then be too small, and would vary from line to line, according to the character of the line at the limb as compared with the centre. Correction for the haze effect can be made by correlating accurate determinations of the relative strengths of haze and limb spectrum with displacements of groups of lines of different intensities. Further investigations may be necessary, but Mr. De Lury appears to be already convinced that variations hitherto ascribed to the sun are mainly due to variations in haze.

The Masses of Visual Binary Stars.-Mr. R. T. A. Innes has been led to some remarkable conclusions by a discussion of data relating to binary stars (South African Journ. Sci., vol. xii., p. 453). All close pairs of stars, with few exceptions, are apparently to be regarded as binaries, whether they show relative motion or not. On the assumption that a binary has the same brightness as the sun, $\mathrm{Mr}$. Innes calculates its distance from the apparent magnitude, and thence the mass, if the period be known. When no orbit has been computed, he proceeds in a similar manner, and calculates the annual angular motion at the distance of the companion which would be produced if the primary had the same mass as the sun. The calculated motion is mostly much in excess of that observed, and Mr. Innes concludes that very few double stars have a mass, or "gravitative power," as he prefers to call it, equal to that of the sun. $\mathrm{He}$ has been led to suppose that gravitative power is small in stars of types $\mathrm{B}$ and $\mathrm{A}$, moderate in F, and large in $\mathrm{G}$ and $\mathrm{K}$ stars; in types $\mathrm{Oe}$ and $\mathrm{M}$ it appears to be absent altogether. The $\mathrm{A}$ type is considered to be poorly represented among binaries, because stars of this class have but little effective gravitative power, notwithstanding their great brilliancy. There appears to be a limiting distance below which double stars cannot exist, and for solar-tvpe stars this is apparently about five times the earth's distance from the sun. It is suggested that light-pressure may partly or wholly neutralise gravitative nower in stars of small density and great luminosity.

\section{MUTATION AND EVOLUTION.}

PROF. ARTHUR DENDY'S presidential address, delivered in February last, before the members of the Quekett Microscopical Club appears in the journal of the club for April, and will probably be much discussed. inasmuch as it is devoted to an analysis of the relation of mutation to the evolution theory, the arguments being based on data drawn from the sponges. The phenomena of mutation, it is con-

$$
\text { NO. 2449, VOL. } 98 \text { ] }
$$

tended, is more a chemico-physical than a bio'ogical phenomenon. Mutations, such as are observable in sponge spicules, in his opinion, strongly suggest the existence of definite factors in the germ plasm. The factorial hypothesis, he considers, is further supported by evidence which is accumulating as to the general course of evolution followed by the Tetraxonida. On the whole this evolution seems to have been progressive, accompanied by increasing complexity or structure, manifested especially in the skeleton. Along certain lines of descent, however, it appears that the culminating point has been passed, and regressive evolution is taking place, resulting in simplification of structure, by the dropping out of certain types of spicule. This loss cannot be regarded as an adaptive modification, nor can it be explained as due to mechanical necessities. Prof. Dendy concludes, therefore, that it is due to some change in the germ-plasm, affecting the power of the sponge to produce the particular spicules in question.

How can we reconcile these facts, it is aslied, with the belief that evolution has taken place, in the main, by slow, successive modifications, rather than by sudden mutations? The conception of factors is intimately bound up with that of mutations, and the existence of the one would seem to imply the occurrence of the other.

As to which set of characters is to be regarded as the more important from the point of view of the student of progressive evolution Prof. Dendy holds there can be little doubt, but how far the division into adaptive and non-adaptive corresponds to the distinction between fluctuating variation and mutation is a different question. Certainly the chances are greatly against a mutation, when it first appears, having any adaptive significance. The evidence seems to him to show that the slow, successive variations of the Darwinian theory have had far more to do with the evolution of sponges than the process of mutation, and are mainly responsible, under the guidance of natural selection, for adaptive modifications.

It is not easy to follow Prof. Dendy in his attempt to discriminate between, and apportion the value of, adaptive and non-adaptive characters. It would seem, however, that he would regard the former as directly affecting viability, in proportion to their responsiveness to the demands of natural selection. They are characters which are of necessity immediately and continuously functional. The latter seem to be regarded as accretions or fortuitous variations, tolerated until they acquire survival value-that is to say, until they come under the sway of natural selection. If this is so, then all non-adaptive characters are potentially adaptive. They afford the basis for further evolutionary phases, or, in other words, the material which will determine the trend of future development and the fate of the organism for good or ill.

W. P. P.

\section{SOME PROBLEMS IN EUGENICS.}

STUDENTS of human heredity from the sociological point of view are indebted to the American Eugenics Record Office (Long Island, N.Y.). Its lastissued Bulletin (No. 15) contains the study of a family indicated by the pseudonym of "Dack," showing markedly a "hereditary lack of emotional control." The author of the bulletin is Mrs. A. W. Finlayson, and Prof. C. B. Davenport contributes a preface in which he emphasises the importance of such "eugenics field-work." Mrs. Finlayson has collected data with regard to 150 descendants of the pair of "Dacks " who emigrated from Ireland to Pennsylvania 
in 1815 , three generations being passed under review. Forty individuals are not recorded to have shown antisocial traits, but the remainder all failed in self-control, many being dishonest, and tending to alcoholism, or to profligacy, forty-one of these being "obviously a burden to society." These objectionable features were most pronounced in the case of offspring of a marriage of first cousins; Prof. Davenport's conclusion that violence of temper is a "dominant" character is confirmed, as in this family it was not found to "skip a generation." Most thoughtful readers of the bulletin will agree with the suggestion at the end of the preface that "unless society steps in and trains the trainable and segregates the uncontrollable, things will go from bad to worse."

Human endowments of a more pleasing kind are discussed by Dr. H. Drinkwater in a paper entitled "Inheritance of Artistic and Musical Ability," published in the last number of the Journal of Genetics (v., No. 4). He gives pedigrees-extending in some cases over four generations-of several families of artists and musicians, which indicate that where both parents are talented all the children inherit the talent, while a non-artistic or non-musical pair never have talented offspring. Hence he infers that artistic or musical ability is a recessive Mendelian character. When only one parent is musical, the number of children showing the recessive character may be more than the 50 per cent. required by the theory, but the records are too few for this to be regarded as a fatal difficulty to Dr. Drinkwater's interpretation. It will, however, be surprising if further research confirms the view that the complex nervous specialisation which must be supposed to accompany marked artistic or musical ability is determined by a simple genetic factor comparable with that which settles the colour of the eyes.

To the Journal of the Royal Statistical Society (vol. Ixxix., part 2) Major Leonard Darwin contributes a paper on the inquiries needed after the war in connection with eugenics. He dwells on the selection of the best men generally for the fighting-line, shows that a higher death-rate may be expected to affect the more daring and self-sacrificing, and points out the meaning for the nation's future of the abnormally heavy losses among officers. His plea for a full investigation of the problem and of possible remedial measures may meet with a disappointing response, but nobody can read his paper and the report of the subsequent discussion-especially after studying the American bulletin summarised above-without realising the "reversed selective action" of the present world-conflict, and perceiving how absolutely opposed to the biological principles enunciated by Major Darwin's great father are those modern "people that delight in war."

G. H. C.

\section{THE BRITISH ASSOCIATION AT NEWCASTLE. \\ SECTION C.}

GEOLOGY.

Opening Address (Abridged) by Prof. W. S. Boulton, D.Sc., F.G.S., President of the Section.

IF we attempt to compare the growth of applied geology in Britain with that, say, in the United States of America, or even in our great self-governing Dominions, or to appraise the knowledge of, and respect for, the facts and principles of geology as directly applicable to industry in these countries and in our own, or to compare the respective literatures on the subject, I think we shall have to confess that we have lagged far behind the position we ought by right of tradition and opportunities now to occupy. The vast natural resources of the countries I have named have doubtless stimulated a corresponding effort in their profitable development. But making due allowance for the fact that Britain is industrially mature as compared with these youthful communities, we cannot doubt that in this special branch of geology, however splendid our advances in others, we have been outstripped by our kinsmen abroad.

To attempt an explanation of this comparative failure to apply effectively the resources of geology to practical affairs would demand a critical analysis of the whole pasition of science in relation to industry and education which is being so vigorously debated by public men to-day. It is unquestionably due, in no small measure, to our ignorance and neglect of, and consequent indifference to, science in general, more especially on the part of our governing classes. This war, with all its material waste and mental anguish, may bring at least some compensation if it finally rouses us from complacence and teaches us to utilise more fully the highly trained and specialised intelligence of the nation.

Here I digress for a moment to lay stress upon a great and needless loss of valuable and detailed knowledge of our Coal Measure geology. It is well known that the Home Office Regulations demand that plans of workings in the different seams at a colliery shall be made and maintained by the colliery officials; and that on the abandonment of the mine copies of such plans shall be kept at the Mines Department of the Home Office for future reference. For ten years, however, they are regarded as confidential. Such information is recorded primarily with a view to the prevention of accidents due to inrushes of water and accumulations of gas.

Unfortunately, as mining men can testify, the plans are often woefully incomplete, inaccurate, and positively misleading as regards such features as faults, rolls, wash-outs, and so forth, and this is notoriously so along the margin of the plans where workings have been abandoned. Cases have been brought to my notice where plans of old workings have been consulted when adjacent ground was about to be explored, and afterwards the plans have proved to be grossly inaccurate, with the consequent risk of serious economic waste. I believe this unfortunate state of things is partly the effect of the complete official severance of the Geological Survey and the Mines Department of the Home Office. When the Geological Survey was first established, and for many years afterwards, a Mining Record Office for the collection and registration of all plans relating to mining operations was attached to it; but afterwards the Mining Record Office was transferred to the Home Office.

I would suggest that it ought to be made possible for all mining plans to be periodically inspected by Government officials with geological knowledge, not merely after the plans are deposited in a Government office, but during the working of the mine; so that, if desirable or necessary; the geological facts indicated by the mine-surveyor on the plan can be tested and verified. If accurate and properly attested plans of old workings were always available, the opening up of new ground would be greatly facilitated and much waste of time and money would be avoided.

Need for Systematic Survey by Deep Boringis.

When we turn our attention to the possible extension of the Coal Measures under the newer strata of SouthCentral England, the geological data at our disposal are lamentably and surprisingly few. Notwithstanding our eagerness to unravel the difficulties, and so to open up new fields for mining activity, very little positive

$$
\text { NO. 2449, VOL. 98] }
$$

